\title{
A life fulfilled: positively influencing physical activity in older adults - a systematic review and meta-ethnography
}

\author{
Gemma S. Morgan ${ }^{1 *} \mathbb{D}$, Micky Willmott ${ }^{1}$, Yoav Ben-Shlomo ${ }^{1}$, Anne M. Haase ${ }^{2}$ and Rona M. Campbell ${ }^{1}$
}

\begin{abstract}
Background: Increasing physical activity in older adults remains a key public health priority in countries with a high burden of non-communicable disease, yet current interventions have failed to substantially increase population uptake with UK data suggesting that only half of 65-74 year olds report meeting recommended levels. The aim of this study was to conduct a systematic and inductive qualitative synthesis of the large body of qualitative research describing what influences physical activity at this age, and older adults' experiences of physical activity.

Methods: A qualitative meta-ethnography was chosen as the study design as this inductive approach can provide novel insights and generate new theory about physical activity and ageing. Papers were identified by searching electronic databases and key citations. Peer-reviewed primary qualitative studies and systematic reviews were included if they met the following inclusion criteria: community-dwelling participants aged 60 years or older or in the retirement transition period; reporting on leisure-time physical activity; utilising a rigorous qualitative methodology. A line of argument approach was employed to generate a theory about how older adults think and feel about physical activity.

Results: Thirty-nine papers met the inclusion criteria and were synthesised. The emergent theory suggested transition to older age can challenge people's sense of self and their role in life. Physical activity can help in regaining feelings of purpose, of being needed in collective group activity, and by creating habitual routine and structure to the day. In overcoming real and perceived barriers, and by taking up or sustaining physical activities, older adults can further build self-esteem all of which contributes to a fulfilling older age.

Conclusion: Current failures to increase population levels of physical activity in older adults may be explained by an approach overly focused on the health benefits of activity. Insights from this study suggest we need to reframe our approach to consider the wider set of goals and aspirations which are of greater personal importance to older adults, and future interventions should focus on how physical activity can contribute to life satisfaction, sense of purpose, and sense of role fulfilment in older age.
\end{abstract}

Trial registration: Registered prospectively on PROSPERO on 29th March 2013: CRD42013003796.

Keywords: Ageing, Physical activity, Qualitative, Meta-ethnography

\footnotetext{
* Correspondence: gemma.morgan@bristol.ac.uk

'Population Health Sciences, Bristol Medical School, University of Bristol,

Bristol BS8 2PS, UK

Full list of author information is available at the end of the article
}

(c) The Author(s). 2019 Open Access This article is distributed under the terms of the Creative Commons Attribution 4.0 International License (http://creativecommons.org/licenses/by/4.0/), which permits unrestricted use, distribution, and reproduction in any medium, provided you give appropriate credit to the original author(s) and the source, provide a link to the Creative Commons license, and indicate if changes were made. The Creative Commons Public Domain Dedication waiver (http://creativecommons.org/publicdomain/zero/1.0/) applies to the data made available in this article, unless otherwise stated. 


\section{Background}

Whilst the scientific and technological progress in reducing premature mortality in high and middle-income countries is welcome, society must prepare for the significant changes this extension of life expectancy will bring to the way our populations are structured. There are vast health, social, and economic implications of an absolute and relative increase in the population of older adults, especially if these individuals are in poor states of health with high levels of frailty and disability [1]. To ameliorate the associated burden on health and social care services it is critical to identify ways of supporting older adults to enjoy active, independent, and happy lives for as long as possible. Emerging evidence suggests that physical activity in later life may prevent, or at least delay, the onset of age-related functional impairment [2-4]. There is a wealth of literature describing different interventions with older adults, of varying delivery method and varied methodological rigour of evaluation. Several small and two large randomised controlled trials (RCTs) [5-12] show some evidence of effectiveness, however, these do not provide definitive evidence because of small sample sizes; self-selecting populations; short follow-up periods; small, inconsistent, or absent effects; or because the interventions are of an intensity and cost that would impede routine implementation. The cited studies [5-12] highlight how research into interventions to increase physical activity amongst older adults has not delivered very impressive results overall. Moreover, there is emerging evidence that the design of the built environment is associated with physical activity levels in older adults [13] and recent research from the United States (US) has highlighted the role of social capital in leisure-time physical activity in those aged over 65 years [14]. New approaches may therefore be required to ensure that behavioural interventions address the principal drivers that affect older adults' behaviour.

A deeper understanding of what physical activity signifies to older adults would enable the development of interventions that acknowledge and address the physical, psychological, and social factors that influence their activity. Qualitative studies can be of considerable value in answering such questions. There is a very large and disparate body of qualitative research in this field to draw on, and there is a need for this to be quality-assessed and assimilated. Integrating or synthesising qualitative research findings can produce new insights not evident in single studies and can generate new theory which can be used to inform the development of new interventions. For example, a meta-ethnography of qualitative research revealed new insights into how patient experiences are shaped by the processes of decision-making and meaning-making. The meta-ethnography indicated ways in which communication between doctors and patients may be facilitated in terms of antidepressant concordance [15]. Theory is important in developing new interventions as evidence suggests that public health or behavioural interventions based on behaviour-change theory are more likely to be effective than those not underpinned by theory [16-18].

Whilst there have been several robust systematic quantitative reviews of the effectiveness of physical activity interventions for older adults, existing qualitative syntheses have been limited in scope, for example focusing only on those of South Asian heritage [19], those with a diagnosis of arthritis [20], those participating in intervention studies [21], and those in transition to retirement [22]. Findings from reviews focused only on these groups may not be generalisable to the wider population of older adults, which will include those who are long retired and those who have never worked. One review, which did not focus on a specific group, contained over a hundred qualitative studies [23]. In-depth and inductive analysis would be impracticable with such a large and wide-ranging set of studies and analysis in this paper was limited to content analysis, which is recognised as a quantitative approach [24]. Whilst that paper provides a useful aggregative summary of the field, a more interpretive synthesis technique can utilise all the rich conceptual data available in individual studies and generate new concepts and theory. Meta-ethnography is one such technique and involves reconceptualisation of the original papers by considering the set of papers as a whole, greater than the sum of their parts [25]. This is achieved by systematically comparing study concepts to identify new overarching concepts and new interpretations [26]. The results of a meta-ethnography may therefore differ considerably from the data contained within the constituent papers as it is interpretive rather than aggregative [25]. Whilst aggregative methods aim to collate, amass, and deduce findings as a way of summarising data, interpretive research is focused on building meaning through integrating the data. In interpretive syntheses, theories and insights are developed through the author's interpretation of the combined findings of the original papers. Barnett-Page and Thomas provide further explanation of the methodologies for synthesising qualitative studies including the spectrum of interpretive and non-interpretive approaches [27].

We aimed to undertake a thorough and comprehensive meta-ethnographic synthesis of high-quality qualitative studies on older adults and physical activity in order to generate theoretical insights which could be used to enhance intervention development in this field.

\section{Methods}

\section{Eligibility criteria}

Papers were included if they were peer-reviewed and reported primary qualitative or mixed methods studies, including systematic reviews. Only papers which focused 
convinced that the findings had been reached from a robust and inductive examination of primary qualitative data). The framework developed by Toye et al. [30] was used to make these decisions, and includes assessment questions such as: whether the concepts are clear and translatable; whether the authors demonstrate interpretive rigour in the analysis; whether the authors describe contradictory data; and what the ethical context of the study is. Papers classed as "fatally flawed" were those which the authors believed contained insufficient detail to be deemed trustworthy.

\section{Data extraction}

A meta-ethnography involves extraction and translation of second-order constructs (the interpretations of the original papers' authors) to generate third-order constructs. Third-order constructs are novel and innovative, and should reveal something about the whole field that is not evident from simply reading the original papers $[15,31]$.

\section{Extracting and translating second-order constructs}

Second-order constructs were extracted by the first author by line-by-line coding of all text under the headings of "Results" or "Findings". Free second-order construct codes were generated de novo to capture the findings described in the text. As new codes were generated, they were juxtaposed with existing codes and a process of refinement, re-classification, and grouping was undertaken. A purposive sample of papers, that is those felt to contribute the greatest to the emerging findings, were double-coded by MW who was blinded to the code set created by GSM. Double-coding was employed to broaden interpretations rather than to confirm or refute the original coding, given that precise agreement is neither likely nor necessary in meta-ethnography [31]. Extracted second-order constructs were then tabulated, systematically considered according to features of the population studied (e.g. gender, age, ethnicity, culture), and translated [15]. The set of translated codes was discussed with co-authors to ensure the data were plausible and comprehensive. A conceptual map was devised, cross-referencing and linking second-order constructs and recording which papers the construct appeared in. Contextual detail was preserved during this mapping phase to allow exploration of relationships between papers and constructs.

\section{Synthesis of translations}

The conceptual map and tabulated translations were then examined as a whole by GSM, to identify how key concepts could be connected, contrasted, and synthesised to create a "line of argument". A "line of argument" is one of several recognised approaches to the final stage of meta-ethnography, and is best defined as "... to offer a fuller account of the phenomenon by arranging the studies' metaphors in some order ... to construct an argument about what the set of ethnographies say" [32]. To facilitate the synthesis, translated concepts were arranged in groups and a "meta-conceptual level" of third-order concepts was created and used to generate the emergent line of argument.

Second-order constructs that appeared to refute or contradict the line of argument were considered to make sense of how they fitted into the emergent theory. Not all second-order constructs were incorporated into the line of argument synthesis. Some papers, most often those of weaker quality, provided conceptually poor data and only rather prosaic second-order constructs could be extracted. Whilst all second-order constructs were considered and translated, those not adding to the emerging theory or contributing to the development of third-order constructs were dropped from the final step of synthesis.

\section{Results}

Search and screening results

Following removal of duplicated records, 5037 title and abstracts were screened by the first author with a random subset $(\geq 10 \%)$ double-screened by a co-author; assessment revealed strong agreement $(\mathrm{K}=0.74)$. After the searches were repeated in October 2016 an additional 974 title and abstracts were screened. A total of 338 papers were subject to full-text review. Following quality appraisal, a final sample of 39 papers were included in the synthesis ( 25 from the original search and 14 from the updated search). The PRISMA diagram is shown in Fig. 2.

\section{Description of papers}

The final sample included thirty-seven primary qualitative papers and two systematic reviews. The characteristics of included papers are listed in Additional file 1: Table S1. Most of the primary studies reported using semi-structured interviews $(n=32)$, other methodologies included focus groups $(n=9)$, ethnography or observations $(n=5)$, and photo-elicitation $(n=2)$; overall number exceeds 37 as many studies used multiple methodologies. The earliest paper included in the sample was published in 1995; 26/39 were published in this decade. None of the included papers focused only on men and five papers had female-only populations. Eleven (28\%) of the study populations were from the United Kingdom (UK) and eleven from the US; only three papers studied populations not from a high-income country and these were Iran $(n=2)$ and China $(n=1)$, both upper-middle-income countries according to the World Bank [33]. Most study samples included a range of ages from 60 to 90 years with a small number $(n=6)$ including 


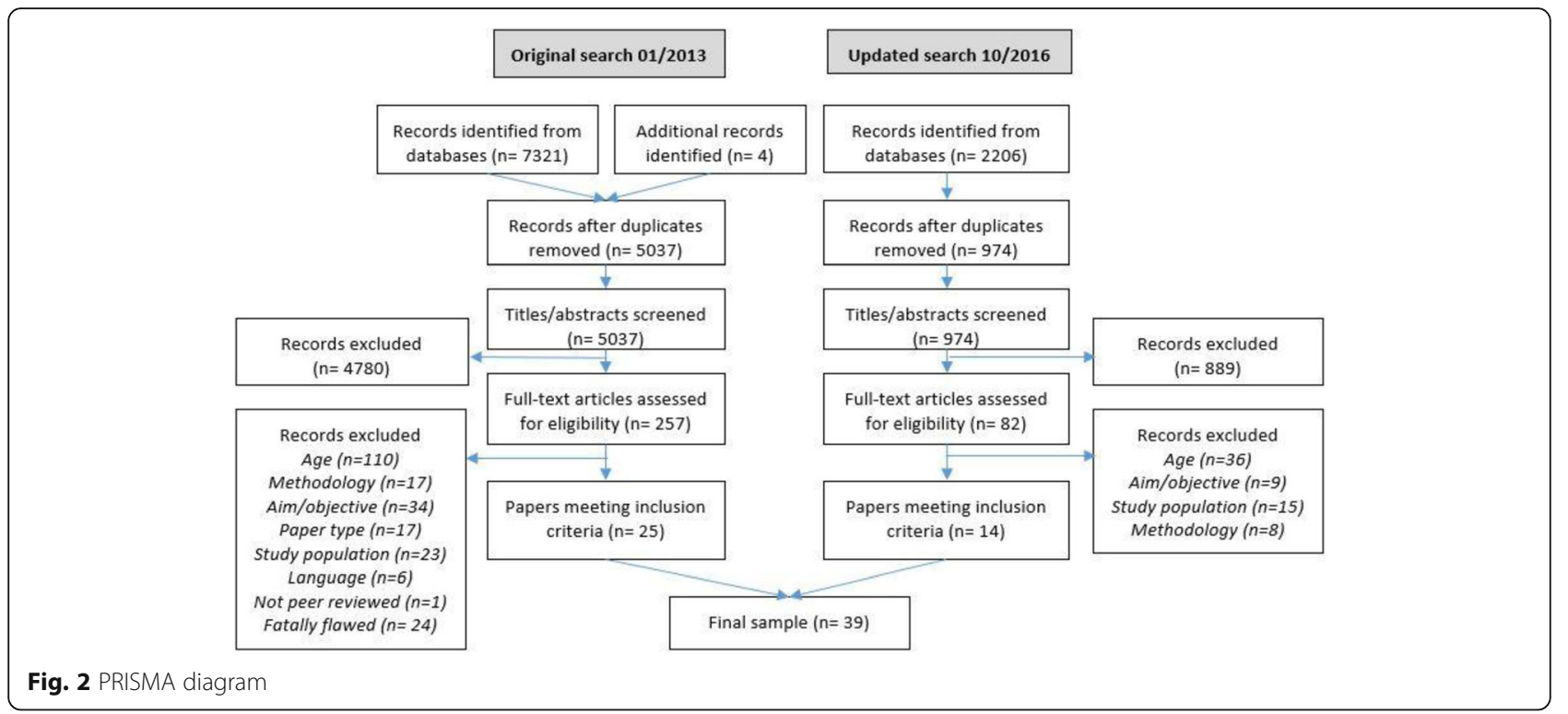

only participants over 70 years. Three papers and one review included some participants who were aged under 60 years; these were all studies about the retirement transition period.

\section{Second- and third-order constructs}

Table 1 lists the key translated second-order constructs retrieved from the papers and tabulated alongside the summary third-order constructs. Five key third-order constructs were interpretively synthesised from the extracted data and were used to generate a line of argument theory:

How physical activity fits in with transition events in ageing Major life events such as ill health [34], retirement [35-37], completion of the caring role for children or grandchildren [38], and bereavement [38] can act as triggers leading to an awareness of ageing and the "body finitude" [39], compounded by negative societal attitudes of older adults and their physical activity: "Young girls in their twenties can be quite rude, but you can still snap back at them if you have a keen mind ... It's just self-absorbed people that dump you in a pile, you're old, we can't be bothered with that sort of attitude" [40]. Physical activity is therefore used to reject stereotypes of ageing [41] and to view ageing through a positive "graceful" lens [42]. Rejection of such stereotypes can occur through taking up new activity in retirement [37, 43-45] ["I don't want to be a little old lady sitting around in a chair" [46]], and this can be invigorating and revitalising, a source of inspiration and energy. Lifelong patterns of activity are important and for some older adults physical activity may provide an opportunity to revisit happy memories of their youth: "One of the good things about this is that you become a teenager again ..." [41].

\section{The role of physical activity in older adults' sense of purpose and self-belief}

Physical activity can bolster self-esteem and strengthen self-identity by adding routines and new roles in ageing [38], by fulfilling a need to keep busy $[47,48]$ and by providing a sense of purpose [49-54] and structure [37, 54] to the lives of older adults: "I get up the same time as I did when I went to work. I do exactly the same thing the only difference is I go out ... to the [swimming pool] and come back but I keep that momentum" [37]. In this sense physical activity may be conceptualised as a responsibility, a duty requiring self-discipline [42, 54] and likened to occupational work [44, 48, 55]: "It's just like a job to me" [55]. Physical activity routines are deemed important by older adults for facilitating sustained activity $[36,43,56]$ and for the associated sense of exercising personal control that these routines can provide $[34,38,39,44,53,57]$ at a time where autonomy and independence may become reduced. The stability or continuity that regular and habitual physical activity affords may counter the changes inherent with ageing such as physical and functional decline, disability, and death of loved ones [41]. The papers revealed how taking up physical activity in later life can provide older adults with feelings of mastery [58], self-belief [53], and satisfaction in overcoming personal challenge $[35,36,44,49,56]$ and simply "getting out and about" and staying busy [38, $44,47-49,52]$ may bolster self-esteem and help avoid feelings of helplessness and futility. 
Table 1 Translated second-order and third-order constructs synthesised and influencing emerging theory

\begin{tabular}{|c|c|}
\hline Translated second-order constructs & References \\
\hline $\begin{array}{l}\text { Life events leading to a change in circumstances or } \\
\text { role and triggering reflection on the new stage of life }\end{array}$ & $\begin{array}{l}{[22,34,37,38,40-42} \\
54,69,72]\end{array}$ \\
\hline $\begin{array}{l}\text { Reflection on lifelong patterns and past experiences with } \\
\text { physical activity, including establishment of healthy habits } \\
\text { early in life }\end{array}$ & $\begin{array}{l}{[22,23,34,36,39-4} \\
46-48,59,62,63,69\end{array}$ \\
\hline $\begin{array}{l}\text { Personal awareness of the ageing body and functional } \\
\text { limitations to independence. Physical activity as a way } \\
\text { of preventing ageing, a source of rejuvenation and } \\
\text { youthfulness, giving new energy }\end{array}$ & $\begin{array}{l}{[34,37,39,41-46} \\
49-51,53,54,57 \\
60,61,67]\end{array}$ \\
\hline $\begin{array}{l}\text { Societal attitudes and stereotypes about ageing and } \\
\text { physical activity }\end{array}$ & {$[40,41,44]$} \\
\hline $\begin{array}{l}\text { Physical appearance in ageing and effects of physical } \\
\text { activity on image }\end{array}$ & {$[41,44,46,54,67]$} \\
\hline Routine and discipline & $\begin{array}{l}{[22,36,37,41-43,} \\
53-56,62,63]\end{array}$ \\
\hline $\begin{array}{l}\text { Undertaking physical activity is a responsibility, like a } \\
\text { job, and gives a sense of purpose }\end{array}$ & $\begin{array}{l}{[36,37,44,48-51} \\
55,62]\end{array}$ \\
\hline $\begin{array}{l}\text { Self-identity, self-esteem / confidence, and personal } \\
\text { development }\end{array}$ & {$[44,46,58,69]$} \\
\hline
\end{tabular}

Self-belief, personal satisfaction, and feelings of mastery in overcoming physical activity challenges

Being busy, having a reason and purpose to leave the house

Taking control over physical activity decisions

Belonging, togetherness

Meeting people socially brings companionship and support

Facilitation of intimate and romantic relationships through physical activity

Competitiveness and fear of others being better

Social and family network inhibiting PA, lack of encouragement, differing views between spouses

Physical health benefits

Pleasure, humour, happiness, fun, self-gratification, mental health benefits, wellbeing

Maintaining an active brain, mental stimulation

Nature, environment, outdoor activity

Music, aesthetics, utilising cultural capital developed over lifetime

Practical barriers (access, facilities, cost, time limitation, weather) and practical support to overcome this from family

Fear of injury, pain, safety, health limitations

Healthcare professionals

$[38,44,47-49,69]$ $53,55]$ $46,49-51,53,55,56$

$[41,54]$

$[23,50,51,62]$

$[37,62,66]$ $71]$ $49,50,54,56,58,61$ $65,67]$

$[41,42,44,51]$

$53,60-64,66,68]$ $69,72,89]$
Summary of third-order construct

How physical activity fits in with transition events

\section{in ageing}

Major life events such as bereavement, retirement, end

of caring role for children or grandchild can act as triggers leading to an awareness of the ageing body. Any negative feelings about ageing may be compounded by societal attitudes, stereotypes, and the expectations of others such as family. However, recognition of this new phase of life can be positive and lead to renewed motivation to stay youthful, maintain energy levels and vitality, and look after the physical body to maintain independence. For those with established physical activity habits, continuing lifelong patterns can facilitate this transition.

$[36,44,49,53,56-58]$

$[34,38,39,44,53,57]$

$[36,41,42,44,49,51$,

$[22,23,36,38,41,42$, $58-61,63-65,67-69]$

The role of physical activity in older adults' sense of purpose and self-belief

Physical activity forms an important part of an older adult's daily routine and is conceptualised as a personal responsibility requiring discipline and taken seriously. In this way physical activity contributes to older adults' role identity and sense of purpose.

Being physically active in older age can provide a sense of personal achievement and satisfaction in mastering a new activity or maintaining an active life despite the challenges of ageing. Physical activity can also provide individuals with satisfaction and personal gratification from a busy life filled with reasons to get up and out of the home.

\section{Physical activity creates and strengthens feelings of togetherness, community, and belonging}

Physical activity provides access to social contact with others, leading to a sense of togetherness, of community, and of belonging to a group. Identifying as a member of a group in this way enhances self-esteem. The structural and functional support, and intimate or sexual relationships associated with shared physical activity further add to feelings of being needed by others. However family concerns and self-comparisons within social networks may impact negatively on physical activity behaviour.

$[22,23,39,40,44-46$, $49,56,58-61,63-69$,

$[22,38,41,42,45,46$,

$[38,57,63-65,69,72]$

\section{Physical activity effects on physical, emotional, and} cognitive health

Health benefits of physical activity are widely accepted and for older adults the value of physical activity in contributing to positive wellbeing through enjoyment, laughter, and pleasure is important. Moreover, older adults are aware of the overlap in physical activity, "getting out and about", and social contact and the positive effects of these on their mental health. Cognitive functions such as maintaining an "active mind" were also felt to be important benefits of an active lifestyle, alongside an appreciation of enriching and aesthetic components of activity including music and nature.

\section{$[23,37,38,43,46,50, \quad$ Barriers to physical activity}

Older adults experience external and logistical barriers to physical activity however these may be overcome with support from others including family. Internal barriers, such as fear of injury and

$[22,23,40,44,48,50$, $53,58-61,64-66,68$, pain, also exist for many and support from respected healthcare professionals can be helpful. 


\section{Physical activity creates and strengthens feelings of togetherness, community, and belonging}

The use of physical activity as an opportunity to increase desired social contact with others [22, 23, 35, 38, 42, 49$52,55,57-61]$, in contributing to intimate relationships [41], and as a source of support $[19,50]$ were also key concepts reported in the papers. The value of being part of a group or community seemed to be linked to a sense of collective togetherness and belonging [41, 42, 44, 53, 55], which can lead to a sense of responsibility as members of the group rely on the attendance of others for support $[49,56]$ : "People will notice and it makes you feel nice ... it makes you feel ... a bit special if people notice that you are not there" [36]. Group membership per se was perceived to be of value to older adults $[36,49,57]$ and was linked to establishment of health-benefitting routines [57, 19] though also held potentially adverse impacts including feelings of not being accepted or fitting in $[22,36]$ and fear of comparisons with others who were more able [23, 50].

The role of family in physical activity experiences in older age can be complex and discordant: practical support, understanding, and enjoyment of doing things with loved ones ["Even when we're away on holiday together you know, we go to places and climb hills and walk..." $[62,19]$ can be valued $[41,46,49,61,63,64]$ but the desire for personal space [62], negative attitudes [37], and being "nagged" by spouses [62] may be detrimental, as can caregiving responsibilities $[51,65]$.

\section{Physical activity effects on physical, emotional, and cognitive health}

Pleasure derived from a feeling of belonging, a purposeful self-identity, and a habitual routine compliments the pleasure that older adults derive directly from the physical activity itself [54, 58]: "You don't know what goes on behind these doors - if only the others could see how we are enjoying ourselves" [41]. For many active older adults, physical activity is associated with feelings of joy [65], laughter [42], and fun, along with perceived improvements to mental health $[35,38,41,45,46,50,51,56,61]$ and keeping one's mind active [39, 41, 44, 51].

The physical health benefits of physical activity are well established and widely acknowledged ( $[22,23$, $39,40,44-46,49,56,58-61,63-71]$ yet physical activity also provides older adults with sensual enjoyment by exposure to music, smells, and touch not otherwise experienced in daily life [41, 54]: "Being in such close contact with my husband when we're dancing is wonderful. I always become very aware of his aftershave and I always like to wear nice perfume" [54]. Similarly, for older adults who find pleasure from being outside and close to nature, physical activity can provide an opportunity to explore this [52, 57, 64, 65, 72]: “... I like just looking at the sky you know, it is wonderful, the big skies are so beautiful. I walk through the fields there. I go for the skies alone" [72]. Pleasure and enjoyment through physical activity appeared not to be any less important to older adults than to younger people; an awareness of mortality associated with ageing may indeed heighten the personal value placed on feelings of pleasure.

\section{Disincentives and barriers to physical activity}

External barriers to older adults' physical activity are real and include time [46, 66] weather [63], cost [37], and structural barriers in the environment [50, 63]: "You are naturally afraid of [walking on] ice, afraid of falling .... You take more care, don't walk as energetically." [63] In addition, older adults can perceive that they might be "doing harm" [65] or overdoing it, causing pain or damage [73]. Mechanisms for overcoming these barriers includes trustworthy advice from facility staff [53] and healthcare professionals [46]. Support from spouses may be a way of overcoming motivational barriers: “... yes I did slow down for about six months, and I would say that I am more sedentary now than I would like to be, but, you know, my wife says I've got to switch that telly off more often and get out and do something ..." [62].

\section{Line of argument}

Using a line of argument approach, our meta-ethnographic synthesis generated a theory of how physical activity fits into the ageing period, as depicted in Fig. 3. This argument asserts that accepting the transition to older age, which may be triggered by an acute event or reached gradually over time, can be a time of turmoil. The realisation that one's role in life and personal identity is changing can leave a sense of loss: of structure, purpose, and control over life; of physical function; and of loved ones. Physical activity can play a part in regaining feelings of purpose and of being needed by engaging older adults in group activity where they feel a sense of responsibility to others, and by creating habitual routine and structure to the day. Taking up or sustaining challenging physical activities in older age can further build self-esteem through mastery and can directly contribute to a fulfilling older age. Moreover, older adults' families and wider society often have firm views and expectations about how older adults should look and behave. These assumptions may be challenged by those seeking a sense of fun and enjoyment in later life, and physical activities are often the mechanism by which these sensations may be realised. Physical activity thus serves as a mediator for a purposeful and engaging older age and should therefore be treated as a means to an end and not as an end in itself. However, given the real and perceived impediments to being more physically active we will need to restructure our social and physical environments to facilitate 


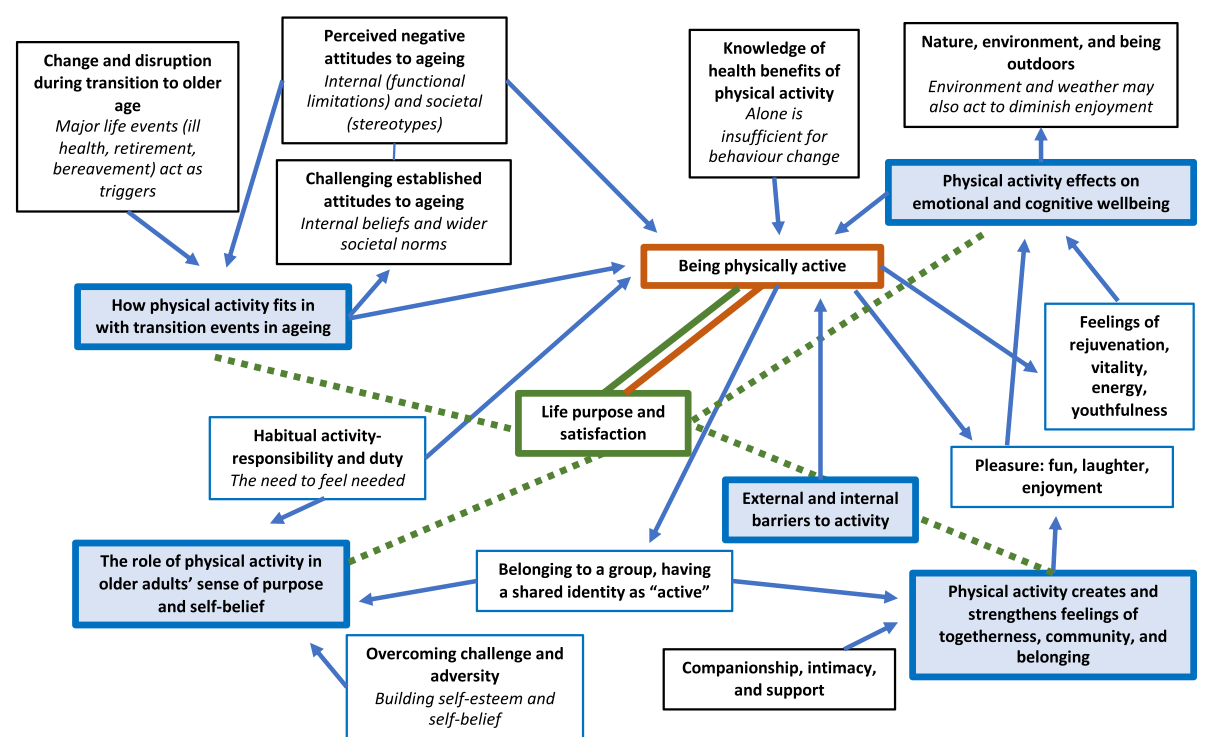

Fig. 3 Line of argument: what physical activity means to older adults

individuals and communities to create this sense of purpose and engage in more physical activity.

\section{Discussion}

\section{Principal findings in context}

Whilst many physical activity messages to older adults focus largely on the protective health benefits [74], our findings suggest that interventions may have more traction with older adults if the emphasis shifts to how physical activity contributes to a purposeful and fulfilling life. We suggest that whilst older adults are aware of the health benefits of being active, there are other drivers for behaviour in older age which may be more powerful as behaviour change levers, such as desiring a sense of purpose and feeling needed by and connected to others.

We present an interpretive qualitative analysis that is theory-generating only; further empirical work would be required to explore the validity of the theoretical constructs presented. However, the findings of our meta-ethnography are aligned with, and complement, existing theories of ageing and of behaviour change.

The classical theories of ageing include the activity theory and social breakdown theory. Activity theory asserts that successful ageing occurs only when adults remain active and socially engaged as they age [75]. The findings of the meta-ethnography largely support the main tenets of activity theory in that older adults attain satisfaction from overcoming challenges and adapting to a life after the loss of previous roles. However, rather than adapting to pursue alternative activities, activity theory proposes that this life satisfaction is achieved by older adults maintaining the activities and lifestyle they had in their younger years. In contrast to this latter point, our findings suggest that lifelong physical activity patterns, whilst helpful, are not necessary and new activities taken up in later life may also lead to life satisfaction. Social breakdown theory [76] reasons that older adults suffer from a loss of identity when their social "labels" are removed, as happens in retirement, with the death of a spouse, or when a caregiving role becomes redundant. Subsequent effects on sense of self-worth and identity may explain why physical activity is not readily taken up in this population. This resonates with the third-order constructs "how physical activity fits in with transition events in ageing" and "the role of physical activity in older adults' sense of purpose and self-belief" [76]. The importance in halting the loss of identity and reconstructing a sense self-worth - through creating challenge and purpose in older age - is supported by the third-order constructs that emerged from the meta-ethnography proposing that physical activities can provide this sense of purpose.

A psychological model of aging, selective optimisation with compensation [77], is also relevant to our findings as this theory - that older adults purposively select activities that are feasible given their physical limitations can be seen as a necessary approach for older adults in successfully reaching new physical activity goals and achieving a sense of competence. Moreover Carstensen's socioemotional selectivity theory [78] suggests that older adults develop a preference for social contact with familiar individuals as they age, as these relationships are rewarding and satisfying. This is consistent with our third-order construct on togetherness and belonging as social contact through physical activity is likely to involve familiarity and will contribute to the sense of being needed and missed by the group when absent from the 
activity. Our findings can also be viewed as complementary to Gullette's sociological discourse on ageing, which describes how Western society has adopted a cultural meaning of ageing as a period of decline. Gullette introduces the terms "progress narrative" and "decline narrative" to describe how society views early and later life respectively [79]. Our findings suggest that physical activity may provide a means by which older adults can turn the negative "decline narrative" into a continued "progress narrative", despite major transition events such as physical changes, new diagnoses, and changing life circumstances.

Many behavioural interventions are based on classic theories such as the health belief model [80], social cognitive theory [81], and theory of planned behaviour [82]. There are elements of unity between our findings and components of these theories - for example the probability of physical activity providing a sense of purpose may be viewed as an "expectancy" in social learning theory and the sense of mastery obtained through physical activity could be seen to affect self-efficacy within the health belief model. However, the findings of our meta-ethnography are not wholly consistent with any classic behavioural change theories. Indeed, recent academic discourse has thrown doubt on the value of at least one of these classic theories in changing behaviour in the real world [83]. On the other hand, the findings of this study are harmonious with a relatively new theory of behaviour change, self-determination theory [84], which purports that for behaviour change to occur an individual's three core psychological needs must be met: the need for competence; the need for relatedness; and the need for autonomy. Whilst self-determination theory is not specific to ageing, these three psychological needs can be viewed as consistent with the third-order constructs retrieved from our synthesis: where physical activity provides a sense of purpose, personal achievement, and self-belief; where physical activity contributes to a sense of togetherness and belonging; and where physical activity routines give a sense of personal responsibility.

\section{Strengths}

This is the first time, to our knowledge, that qualitative literature on physical activity and ageing has been brought together and synthesised using meta-ethnography. Our findings resonate with elements of other theories however this synthesis provides unity of theory, relating specifically to physical activity in ageing. A second key strength of this review is the use of the meta-ethnographic method to re-conceptualise the subject, whilst remaining empirically grounded in the second-order constructs from the constituent papers. As an interpretive synthesis of the primary research, our findings provide different insights to the concepts published in other qualitative syntheses [19-21, 23]. Whilst we describe a new overarching way of considering physical activity in older adults, elements of our findings have been reported by others, for examples in a recent review of studies of physical activity interventions for older adults the authors concluded that engagement may be increased by presenting interventions as fun, sociable, and achievable [21]. This conclusion supports one of the third-order constructs in our synthesis: the value of physical activity in creating feelings of pleasure and wellbeing.

The reliability of a systematic review is related to the quality of its component studies. Whilst we recognise that some view quality assessment of qualitative research as controversial from a relativist position, it can also be argued that if the findings of qualitative syntheses are to be used to influence health and public health policy, then we must be sufficiently confident that the findings of the individual papers making up the synthesis are trustworthy. Our evaluation of study quality using an appropriate framework, attempting to ensure that the included findings have integrity and a degree of dependability, is therefore a further strength of this study.

\section{Limitations}

Despite a comprehensive and updated literature search, it is always possible that some important studies were not identified, and key constructs therefore not analysed. The exclusion of studies not published in English is a limitation of this study, and the small contribution of research from upper middle-income countries means the findings might not be generalizable to all populations. Whilst these papers were readily synthesisable with those from high-income countries it is possible that if the sample of papers from non-high-income countries had been larger, greater heterogeneity may have emerged. Furthermore, with globalisation and the epidemiological transition in lower income countries, the prevalence of non-communicable diseases - and associated risk factors including low physical activity levels - increases [85]. It is therefore possible that the findings will become increasingly applicable to many lower-income countries however it is important to test this and more primary research in those countries would be welcomed. Further high-quality, primary qualitative research on physical activity and ageing from non-high-income countries would enable the meta-ethnography to be updated to include a greater diversity of settings.

It was not possible to comment on whether there are differences by gender as only a small number of studies involved female-only populations (and none male-only), the original primary papers did not provide findings stratified by gender, nor did they include sufficient detail on whether gender was an important conceptual differentiator. 
In addition, meta-ethnography, as an interpretivist approach, will be influenced to some degree by the authors' own experiences, perspectives, and preconceptions. To reduce undue influence over the data interpretation and theory-building, a transparent, referenced, and fully-documented analytical methodology was employed, and emergent constructs were discussed and checked amongst the study team.

We were unable to quantify the physical activity levels of the participants included in the synthesised papers. Our eligibility criteria ensured that "master athletes"those older adults competing at elite levels - were not included in the synthesis, yet it is possible that the level of physical activity and fitness still varied considerably amongst participants in the included studies. Nevertheless, the constructs derived from these studies should be relevant to older adults across the activity spectrum, and the heterogeneity of the study populations is likely to mirror the heterogeneity of the wider older adult population.

\section{Implications and unanswered questions}

Increasing physical activity levels amongst adults of all ages, including those aged over 65 , is a public health priority. In the UK, current National Health Service (NHS) guidelines recommend adults over 65 who are generally fit with no health conditions should undertake at least $150 \mathrm{~min}$ of moderate aerobic activity, for example cycling or walking, every week. The latest self-report data published by the Health Survey for England in 2016 reveal that less than half (44\%) of the population aged over 65 are meeting this target and the proportion reduces further for those aged 75 years and older (30\%) [86]. Our study adds value to the field as our findings provide a plausible explanation for why physical activity levels amongst older adults remain low despite investment in public health programmes and interventions.

The findings presented in this synthesis suggest that physical activity should be framed as a mechanism for supporting a purposeful, socially-connected, and usefully engaged life in older age. As such it provides public health practitioners and gerontologists with an approach, grounded in qualitative data, upon which new programmes and interventions can be developed. Our findings may be used to develop or enhance interventions at the level of the individual, community, or population by reframing the focus to better meet older adults' motivations. Indeed, a recent paper using qualitative methods to develop a typology of older adults' motivations for physical activity also included reference to those seeking "purposeful" activity [87].

Further work is required to explore how interventions can incorporate the constructs presented in this paper. An approach moving away from the paternalistic "physical activity for health" message is necessary yet replacing this with a paternalistic "physical activity for purpose" message is unlikely to be effective. Public health specialists will need to create environments in which older adults can both recognise the value of a physically active lifestyle and be enabled to change their behaviour to receive these wider benefits. Age-friendly cities and communities [88] provide a useful framework within which public health specialists and academics can develop and implement physical activity interventions. Comprehensive evaluation of such interventions will provide better understanding of how the third-order constructs identified in this synthesis can effect change at an individual and population level and will lead to the delivery of more effective and sustainable programmes to improve physical activity levels amongst older adults in the longer term.

\section{Conclusions}

Existing physical activity interventions for older adults often emphasise the health benefits as a means of encouraging behaviour change. This meta-ethnography suggests that for older adults, such a focus may be misplaced because at this stage in their lives older adults have other goals which are of greater personal importance. Physical activity however can be a means by which these goals may be obtained. We therefore suggest that for an intervention to effectively increase and sustain physical activity levels in older adults a shift in focus is required. We advocate an approach in which older adults are supported to regain or consolidate their sense of purpose through the routines, personal achievement, and meaningful social connections physical activity can provide.

\section{Additional file}

Additional file 1: Table S1. Description of papers included in metaethnography. (DOCX $20 \mathrm{~kb}$ )

\section{Abbreviations}

NHS: National Health Service; PRISMA: Preferred Reporting Items for Systematic Reviews and Meta-Analyses; RCT: Randomised controlled trial; UK: United Kingdom; US: United States

\section{Acknowledgements}

Heide Busse assisted with the identification of papers in the original electronic database search by double-screening a random sample of titles and abstracts.

\section{Funding}

This research was funded by the National Institute of Health Research (NIHR) through a doctoral research fellowship (DRF-2012-05-123). The views expressed in this publication are those of the authors and not necessarily those of the NHS, the National Institute for Health Research or the Department of Health and Social Care (DHCS).

The work was undertaken with the support of the Centre for the Development and Evaluation of Complex Interventions for Public Health Improvement (DECIPHer), a UKCRC Public Health Research Centre of Excellence. Funding from the British Heart Foundation, Cancer Research UK, 
Economic and Social Research Council (RES-590-28-0005), Medical Research Council, the Welsh Assembly Government and the Wellcome Trust (WT087640MA), under the auspices of the UK Clinical Research Collaboration, is gratefully acknowledged.

The funders had no role in the design of the study or the collection, analysis, interpretation of the data, or in writing the manuscript.

\section{Availability of data and materials}

Please contact the corresponding author with requests.

\section{Authors' contributions}

GSM, MW, YBS, AMH, and RMC have made substantive intellectual contributions to the study. GSM, RC, YBS, and AMH designed the study. GSM, MW, $\mathrm{RC}$, and YBS made substantial contributions to the analysis and interpretation of the data. All authors read and approved the final manuscript.

\section{Ethics approval and consent to participate}

Not applicable

\section{Consent for publication}

Not applicable

\section{Competing interests}

Rona Campbell is a Scientific Advisor of DECIPHer Impact limited, a not-forprofit company, wholly owned by the Universities of Bristol and Cardiff, which exists to license and support the implementation of evidence-based public health interventions. The remaining authors declare that they have no competing interests.

\section{Publisher's Note}

Springer Nature remains neutral with regard to jurisdictional claims in published maps and institutional affiliations.

\section{Author details}

'Population Health Sciences, Bristol Medical School, University of Bristol, Bristol BS8 2PS, UK. ${ }^{2}$ School of Policy Studies, University of Bristol, Bristol BS8 $1 \mathrm{TZ}, \mathrm{UK}$.

Received: 11 September 2018 Accepted: 5 March 2019

Published online: 02 April 2019

\section{References}

1. Wanless D. Securing good Care for Older People: taking a long-term view. The Kings Fund. 2006 (https://www.kingsfund.org.uk/publications/securing good-care-older-people). Accessed 13 Mar 2019.

2. Miller ME, Rejeski WJ, Reboussin BA, Ten Have TR, Ettinger WH. Physical activity, functional limitations, and disability in older adults. J Am Geriatr Soc. 2000;48(10):1264-72.

3. Hamer M, Lavoie KL, Bacon SL. Taking up physical activity in later life and healthy ageing: the English longitudinal study of ageing. Br J Sports Med. 2014:48(3):239-43.

4. Leveille SG, Guralnik JM, Ferrucci L, Langlois JA. Aging successfully until death in old age: opportunities for increasing active life expectancy. Am J Epidemiol. 1999;149(7):654-64.

5. Foster C, Hillsdon M, Thorogood M, Kaur A, Wedatilake T. Interventions for promoting physical activity. Cochrane Database Syst Rev. 2005;(1). Art. No. CD003180. https://doi.org/10.1002/14651858.CD003180.pub2.

6. Pahor M, Guralnik JM, Ambrosius WT, Blair S, Bonds DE, Church TS, et al. Effect of structured physical activity on prevention of major mobility disability in older adults: the LIFE study randomized clinical trial. Jama. 2014; 311(23):2387-96.

7. Giné-Garriga M, Roqué-Fíguls M, Coll-Planas L, Sitjà-Rabert M, Salvà A. Physical exercise interventions for improving performance-based measures of physical function in community-dwelling, frail older adults: a systematic review and meta-analysis. Arch Phys Med Rehabil. 2014;95(4):753-69 e3.

8. Landi F, Cesari M, Calvani R, Cherubini A, Di Bari M, Bejuit R, et al. The "sarcopenia and physical fRailty IN older people: multi-componenT treatment strategies"(SPRINTT) randomized controlled trial: design and methods. Aging Clin Exp Res. 2017;29(1):89-100.
9. Olanrewaju O, Kelly S, Cowan A, Brayne C, Lafortune L. Physical activity in community dwelling older people: a systematic review of reviews of interventions and context. PLoS One. 2016;11(12):e0168614.

10. Hinrichs T, Bücker B, Klaaßen-Mielke R, Brach M, Wilm S, Platen P, et al. Home-based exercise supported by general practitioner practices: ineffective in a sample of chronically ill, mobility-limited older adults (the HOMEfit randomized controlled trial). J Am Geriatr Soc. 2016;64(11):2270-9.

11. Warner LM, Wolff JK, Ziegelmann JP, Schwarzer R, Wurm S. Revisiting selfregulatory techniques to promote physical activity in older adults: nullfindings from a randomised controlled trial. Psychol Health. 2016;31(10): 1145-65.

12. Gill TM, Baker DI, Gottschalk M, Peduzzi PN, Allore H, Byers A. A program to prevent functional decline in physically frail, elderly persons who live at home. N Engl J Med. 2002;347(14):1068-74.

13. Barnett DW, Barnett A, Nathan A, Van Cauwenberg J, Cerin E. Built environmental correlates of older adults' total physical activity and walking: a systematic review and meta-analysis. Int J Behav Nutr Phys Act. 2017;14(1):103.

14. Yu C-Y, Hou S-I, Miller J. Health for older adults: the role of social capital and leisure-time physical activity by living arrangements. J Phys Act Health. 2018;15(2):150-8.

15. Malpass A, Shaw A, Sharp D, Walter F, Feder G, Ridd M, et al. "Medication career" or "moral career"? The two sides of managing antidepressants: a meta-ethnography of patients' experience of antidepressants. Soc Sci Med. 2009;68(1):154-68

16. Taylor N, Conner M, Lawton R. The impact of theory on the effectiveness of worksite physical activity interventions: a meta-analysis and meta-regression. Health Psychol Rev. 2012;6(1):33-73.

17. Webb T, Joseph J, Yardley L, Michie S. Using the internet to promote health behavior change: a systematic review and meta-analysis of the impact of theoretical basis, use of behavior change techniques, and mode of delivery on efficacy. J Med Internet Res. 2010;12(1):e4.

18. Glanz K, Bishop DB. The role of behavioral science theory in development and implementation of public health interventions. Annu Rev Public Health. 2010;31:399-418.

19. Horne M, Tierney S. What are the barriers and facilitators to exercise and physical activity uptake and adherence among south Asian older adults: a systematic review of qualitative studies. Prev Med. 2012;55(4):276-84.

20. Beckwée D, Vaes P, Cnudde M, Swinnen E, Bautmans I. Osteoarthritis of the knee: why does exercise work? A qualitative study of the literature. Ageing Res Rev. 2013:12(1):226-36.

21. Devereux-Fitzgerald A, Powell R, Dewhurst A, French DP. The acceptability of physical activity interventions to older adults: a systematic review and meta-synthesis. Soc Sci Med. 2016;158:14-23.

22. Barnett I, Guell C, Ogilvie D. The experience of physical activity and the transition to retirement: a systematic review and integrative synthesis of qualitative and quantitative evidence. Int J Behav Nutr Phys Act. 2012;9(1):97.

23. Franco MR, Tong A, Howard K, Sherrington C, Ferreira PH, Pinto RZ, et al. Older people's perspectives on participation in physical activity: a systematic review and thematic synthesis of qualitative literature. Br J Sports Med. 2015.

24. Berelson B. Content analysis in communication research; 1952.

25. Noblit GW, Hare RD. Meta-ethnography: synthesizing qualitative studies: sage; 1988.

26. France EF, Ring N, Noyes J, Maxwell M, Jepson R, Duncan E, et al. Protocoldeveloping meta-ethnography reporting guidelines (eMERGe). BMC Med Res Methodol. 2015;15(1):103.

27. Barnett-Page $E$, Thomas J. Methods for the synthesis of qualitative research: a critical review. BMC Med Res Methodol. 2009;9(1):59.

28. Thomas J, Brunton J, Graziosi S. EPPI-reviewer 4: software for research synthesis. EPPI-Centre Software 2010.

29. Murphy E, Dingwall R, Greatbatch D, Parker S, Watson P. Qualitative research methods in health technology assessment: a review of the literature. Health Technol Assess. 1999:2(16):276.

30. Toye F, Seers K, Allcock N, Briggs M, Carr E, Andrews J, et al. 'Trying to pin down jelly' - exploring intuitive processes in quality assessment for metaethnography. BMC Med Res Methodol. 2013;13(1):46.

31. Campbell R, Pound P, Morgan M, Daker-White G, Britten N. Evaluating metaethnography: systematic analysis and synthesis of qualitative research. Health Technol Assess. 2011;15(43):164.

32. Thorne S, Jensen L, Kearney MH, Noblit G, Sandelowski M. Qualitative Metasynthesis: reflections on methodological orientation and ideological agenda. Qual Health Res. 2004;14(10):1342-65. 
33. The World Bank Group. World Bank Country and Lending Groups [Available from: https://datahelpdesk.worldbank.org/knowledgebase/articles/906519. Accessed 13 Mar 2019.

34. Kenter EJ, Gebhardt WA, Lottman I, van Rossum M, Bekedam M, Crone MR The influence of life events on physical activity patterns of Dutch older adults: a life history method. Psychol Health. 2015;30(6):627-51.

35. Barnett I, van Sluijs E, Ogilvie D. Physical activity and transitioning to retirement: a systematic review. Am J Prev Med. 2012;43:329-36.

36. Beck F, Gillison F, Standage M. A theoretical investigation of the development of physical activity habits in retirement. Br J Health Psychol. 2010;15(3):663-79.

37. McDonald S, O'Brien N, White M, Sniehotta FF. Changes in physical activity during the retirement transition: a theory-based, qualitative interview study. Int J Behav Nutr Phys Act. 2015;12(1):25.

38. Bidonde MJ, Goodwin DL, Drinkwater DT. Older Women's Experiences of a Fitness Program: The Importance of Social Networks. J Appl Sport Psychol. 2009;21(sup1):S86-S101.

39. Dumas A, Laberge S. Social class and ageing bodies: understanding physical activity in later life. Soc Theory Health. 2005;3(3):183-205.

40. Jancey JM, Clarke A, Howat P, Maycock B, Lee AH. Perceptions of physical activity by older adults: a qualitative study. Health Educ J. 2009:68(3): 196-206.

41. Cooper $L$, Thomas H. Growing old gracefully: social dance in the third age. Ageing Soc. 2002;22(06):689-708.

42. Paulson S. How various "cultures of fitness" shape subjective experiences of growing older. Ageing Soc. 2005;25(02):229-44.

43. Price $A E$, Greer B, Tucker A. Older black women's experiences initiating and maintaining physical activity: implications for theory and practice. J Aging Phys Act. 2013;21(3):348-66.

44. Rydeskog A, Frändin K, Hansson SM. Elderly people's experiences of resistance training. Adv Physiother. 2005;7(4):162-9.

45. Wagstaff S. Supports and barriers for exercise participation for well elders: implications for occupational therapy. Phys Occup Ther Geriatr. 2006;24(2): 19-33.

46. Grossman MD, Stewart AL. "you aren't going to get better by just sitting around": physical activity perceptions, motivations, and barriers in adults 75 years of age or older. Am J Geriatr Cardiol. 2003;12(1):33-7.

47. Witcher C, Holt N, Spence J, Cousins S. A case study of physical activity among older adults in rural Newfoundland, Canada. J Aging Phys Act. 2007; 15(2):166-83.

48. Witcher CS, Holt NL, Young W, Blanchard C, Murnaghan D, Spence JC. Physical activity perceptions and influences among older adults in rural Nova Scotia. Can J Aging. 2016;35(01):115-29.

49. Grant BC. An insider's view on physical activity in later life. Psychol Sport Exerc. 2008;9(6):817-29.

50. Costello E, Kafchinski M, Vrazel J, Sullivan P. Motivators, barriers, and beliefs regarding physical activity in an older adult population. J Geriatr Phys Ther. 2011;34(3):138-47.

51. Guell C, Shefer G, Griffin S, Ogilvie D. 'Keeping your body and mind active': an ethnographic study of aspirations for healthy ageing. BMJ Open. 2016; 6(1):e009973.

52. Leavy B, Åberg A. "Not ready to throw in the towel": perceptions of physical activity held by older adults in Stockholm and Dublin. J Aging Phys Act. 2018;18(2):219-36

53. Lübcke A, Martin C, Hellström K. Older adults' perceptions of exercising in a senior gym. Act Adapt Aging. 2012;36(2):131-46.

54. Phoenix C, Orr N. Pleasure: a forgotten dimension of physical activity in older age. Soc Sci Med. 2014;115:94-102.

55. Duncan HH, Travis SS, McAuley WJ. An emergent theoretical model for interventions encouraging physical activity (mall walking) among older adults. J Appl Gerontol. 1995;14(1):64-77.

56. Horne M, Skelton DA, Speed S, Todd C. Attitudes and beliefs to the uptake and maintenance of physical activity among community-dwelling south Asians aged 60-70 years: a qualitative study. Public Health. 2012;126(5):41723.

57. Franke T, Tong C, Ashe MC, McKay H, Sims-Gould J, Team TWTT. The secrets of highly active older adults. J Aging Stud. 2013;27(4):398-409.

58. Stathi A, McKenna J, Fox KR. The experiences of older people participating in exercise referral schemes. J R Soc Promot Heal. 2004;124(1):18-23.

59. Alizadeh L, Salehi L. Older People's perspectives on health, physical activity and nutritional behaviors. Health Promot Perspect. 2015;5(4):288.
60. Lavizzo-Mourey R, Cox C, Strumpf N, Edwards WF, Lavizzo-Mourey R, Stinemon $\mathrm{M}$, et al. Attitudes and beliefs about exercise among elderly African Americans in an urban community. J Natl Med Assoc. 2001;93(12): 475-80.

61. Li Y, Du X, Zhang C, Wang S. Physical activity among the elderly in China: a qualitative study. Br J Community Nurs. 2013;18(7):340-50.

62. Barnett I, Guell C, Ogilvie D. How do couples influence each other's physical activity behaviours in retirement? An exploratory qualitative study. BMC Public Health. 2013;13(1):1197.

63. Bjornsdottir G, Arnadottir SA, Halldorsdottir S. Facilitators of and barriers to physical activity in retirement communities: experiences of older women in urban areas. Phys Ther. 2012;92(4):551-62.

64. Sebastião E, Chodzko-Zajko W, Schwingel A. An in-depth examination of perceptions of physical activity in regularly active and insufficiently active older African American women: a participatory approach. PLoS One. 2015; 10(11):e0142703

65. Welmer A, Morck A, Dahlin-Ivanoff S. Physical activity in people age 80 years and older as a means of counteracting disability, balanced in relation to frailty. J Aging Phys Act. 2012;20(3):317-31.

66. Abolfazl R, Monireh A, Fazlollah A, Mahshid F. Exercise and physical activity among healthy elderly Iranians. Southeast Asian J Trop Med Public Health. 2011;42(2):444-55.

67. Henwood T, Tuckett A, Edelstein O, Bartlett H. Exercise in later life: the older adults' perspective about resistance training. Ageing Soc. 2011;31(08):133049.

68. Horne M, Skelton DA, Speed S, Todd C. Perceived barriers to initiating and maintaining physical activity among south Asian and White British adults in their 60 s living in the United Kingdom: a qualitative study. Ethnicity Health. 2013;186(6):626-45.

69. Leavy B, Aberg A. "not ready to throw in the towel": perceptions of physical activity held by older adults in Stockholm and Dublin. J Aging Phys Act. 2010;18(2):219-36

70. Liu CJ, Latham NK. Progressive resistance strength training for improving physical function in older adults. Cochrane Database Syst Rev. 2009;(3). Art. No.: CD002759. https://doi.org/10.1002/14651858.CD002759.pub2.

71. Liu Z, Speed S, Beaver K. Perceptions and attitudes towards exercise among Chinese elders-the implications of culturally based self-management strategies for effective health-related help seeking and person-centred care. Health Expect. 2015;18(2):262-71.

72. Grant TL, Edwards N, Sveistrup H, Andrew C, Egan M. Neighborhood walkability: older people's perspectives from four neighborhoods in Ottawa. Canada J Aging Phys Act. 2010;18(3):293-312.

73. Chalder M, Wiles NJ, Campbell J, Hollinghurst SP, Haase AM, Taylor AH, et al Physical activity as a treatment for depressed adults: randomised controlled trial. Br Med J. 2011.

74. Chief Medical Officers of England S, Wales, and Northern Ireland. Start Active, Stay Active: A report on physical activity for health from the four home countries' Chief Medical Officers. 2011.

75. Havighurst RJ. Successful Aging. The Gerontologist. 1961;1(1):8-13.

76. Kuypers JA, Bengtson VL. Social breakdown and competence. Hum Dev. 1973:16(3):181-201.

77. Baltes PB, Baltes MM. Psychological perspectives on successful aging: The model of selective optimization with compensation. In: Successful Aging: Perspectives from the Behavioral Sciences: Cambridge University Press; 1990. p. 1-34

78. Carstensen LL, Fung HH, Charles ST. Socioemotional selectivity theory and the regulation of emotion in the second half of life. Motiv Emot. 2003;27(2): 103-23.

79. Gullette MM. Aged by culture: University of Chicago Press; 2004.

80. Rosenstock IM, Strecher VJ, Becker MH. Social learning theory and the health belief model. Health Educ Q. 1988;15(2):175-83.

81. Bandura A. Self-efficacy: toward a unifying theory of behavioral change. Psychol Rev. 1977;84(2):191-215.

82. Ajzen I. The theory of planned behavior. Organ Behav Hum Decis Process. 1991;50(2):179-211.

83. Sniehotta FF, Presseau J, Araújo-Soares V. Time to retire the theory of planned behaviour? Health Psychol Rev. 2014;8(1):1-7.

84. Ryan RM, Deci EL. Self-determination theory and the facilitation of intrinsic motivation, social development, and well-being. Am Psychol. 2000;55(1):68

85. Organization WH. Back ground paper: non communicable diseases in low and middle income countries. Geneva: WHO; 2010. 
86. NHS Digital. Health Survey for England, 20162017 [Available from: https:// digital.nhs.uk/data-and-information/publications/statistical/health-survey-forengland/health-survey-for-england-2016. Accessed 13 Mar 2019.

87. Guell C, Panter J, Griffin S, Ogilvie D. Towards co-designing active ageing strategies: A qualitative study to develop a meaningful physical activity typology for later life. Health Expect. 2018;21(5):919-26.

88. World Health Organization. Global age-friendly cities: A guide. 2007.

89. Horne M, Skelton D, Speed S, Todd C. The influence of primary health care professionals in encouraging exercise and physical activity uptake among White and south Asian older adults: experiences of young older adults. Patient Educ Couns. 2010;78(1):97-103.

- fast, convenient online submission

- thorough peer review by experienced researchers in your field

- rapid publication on acceptance

- support for research data, including large and complex data types

- gold Open Access which fosters wider collaboration and increased citations

- maximum visibility for your research: over $100 \mathrm{M}$ website views per year

At $\mathrm{BMC}$, research is always in progress. 